\title{
Is Online Teaching in the First Two Years of the Medical School During the COVID-19 Pandemic Serving the Purpose?
}

\section{Sateesh Babu Arja ( $\square$ sarja@avalonu.org )}

Avalon University School of Medicine https://orcid.org/0000-0001-8692-3348

\section{Samir Fatteh}

Avalon University School of Medicine

\section{Sailaja Nandennagari}

Avalon University School of Medicine

\section{Sai Sarath Kumar Pemma}

Avalon University School of Medicine

\section{Kumar Ponnusamy}

Avalon University School of Medicine

\section{Sireesha B. Arja}

Avalon University School of Medicine

\section{Research article}

Keywords: COVID-19, Medical Education, Basic Science, Teaching and Learning, Evaluation

Posted Date: March 22nd, 2021

DOI: https://doi.org/10.21203/rs.3.rs-333593/v1

License: (c) (i) This work is licensed under a Creative Commons Attribution 4.0 International License. Read Full License 


\section{Abstract}

\section{Background}

COVID-19 pandemic has required a major and rapid shift in teaching and training methods across health professions education. Physical distancing and closure of campuses required online teaching to replace face-to-face teaching. This study aims to investigate if online teaching implemented in the first two years of the medical school at Avalon University School of Medicine is serving the purpose during the COVID-19 pandemic.

\section{Methods}

This is a concurrent mixed research method. The quantitative data collected are course evaluations and students' performance in assessments between the two semesters September 2019 and May 2020, which had on-campus and online teaching, respectively. Qualitative data were collected using individual interviews of 19 faculty members and students. The quantitative data were analyzed for $p$-values and statistical significance using a t-test. The qualitative data were analyzed using thematic analysis.

\section{Results}

Results have shown no statistically significant difference $(p<0.05)$ between two semesters for course evaluations. Even if there is any difference, the mean values were better in May 2020 semester with online teaching. There was no statistically significant difference $(p<0.05)$ even on students' performance in assessments except for two courses. The thematic analysis of interviews revealed the advantages and disadvantages of online teaching.

\section{Conclusions}

Online teaching is serving the purpose in the first two years of the medical school during the COVID-19 pandemic. The advantages of online teaching are flexibility and comfort, and students can save time. The disadvantages are technical challenges, students lacking motivation, lack of personal interaction, and limitations on lab and hands-on experiences.

\section{Introduction}

COVID-19 pandemic necessitated a significant and rapid shift in teaching and learning strategies across health professions education and educational programs worldwide. Significantly, the need for physical distancing severely constrained traditional face-to-face lectures and teaching strategies and encouraged a shift to be online and virtual teaching strategies $[1,2,3,4]$. COVID-19 pandemic situation posed many challenges to healthcare worldwide and medical education. Rose observed that 'The need to prepare future physicians has never been as focused as it is now in a global emergency' [5]. The COVID-19 pandemic caused worldwide disruptions to the healthcare system and medical education $[5,6]$. 
Institutions of higher learning stopped operations physically, and most of the activities are online. Further, the response of medical schools to the COVID-19 pandemic was unprecedented.

Avalon University School of Medicine (AUSOM) is a medical school established in Curacao, the Caribbean region offering a Doctor of Medicine (M.D.) program. The M.D. program is of 4-year duration, with the first two years including basic science instruction and the next two years of clinical rotations/clerkships. The first two years of the program consist of basic science courses, including clinical skills. Basic science courses are spread over five semesters, which are from MD1 to MD5 semesters. Basic science courses include multi-disciplinary courses like Human Structure and Function (HSF) 1 and 2 (anatomy, histology, and physiology), Molecular Basis of Medicine (MBM) 1 and 2 (biochemistry and genetics), Mind, Brain, and Behavior (MBB) 1 and 2 (neuroscience and genetics), Diseases, Immunity, and Therapeutics (DIT) 1 and 2 (pharmacology, pathology and microbiology and immunology), epidemiology and biostatistics and clinical skills 1-4.

The Medical Education Unit (MEU) and dean's office, in collaboration with the Information Technology (IT) department at AUSOM, provided training and resources for biomedical faculty to develop skills and expertise for delivering courses in virtual teaching methods. These actions were taken for the rapid transition to teaching and learning in virtual environments during the COVID-19 pandemic. In this context, drawing on faculty development program experiences and support during the COVID-19 which caused rapid teaching transition, we handled very innovative teaching strategies in virtual environments. We designed and trained the faculty who are both relatively new to virtual teaching and had prior hands-on experience. Faculty with previous experience potentially benefit from new and different perspectives on the application and impact of education through technology presented below.

\section{Online teaching platforms}

Both content experts and the students needed to adapt to the new normal of using available tools on the internet to continue education [7]. Popular platforms or software that were frequently used were WebEx®, Microsoft Teams ${ }^{\circledR}$, Zoom ${ }^{\circledR}$, and Google Meet ${ }^{\circledR}$ as these were provided free of charge. For example, Zoom ${ }^{\circledR}$ has forgone its time limit to use the Zoom ${ }^{\circledR}$ application widely. But these also have their limitations given vast usage around the globe as the whole world was being locked down [8]. We have been using Google Meet ${ }^{\circledR}$ at AUSOM. Assessments were conducted online using the Google Meet application and video-based proctoring.

\section{Methods of online teaching}

Methods of online teaching and learning in medicine were primarily divided into two, which are synchronous and asynchronous teaching. Synchronous instruction is where the lecturer teaches and communicates with the students in real-time online using various video conference applications. Asynchronous teaching is where the lecturers recorded their lectures or hands-on clinical examinations or set up tasks and assignments for students to complete at a specified time. It is not on a real-time basis. These two methods also have their limitations, mainly due to internet availability, connectivity, and time 
difference $[9,10]$. At AUSOM, the main teaching method during this pandemic was synchronous teaching supplemented with recorded video libraries like 'Lecturio.'

For pre-clinical teaching, which is integrated with United States Medical Licensing Examinations (USMLE) preparatory curriculum, usually requires clinical exposure and clinical skills right from the beginning. Online teaching posed a moderate challenge to this. Many universities evolved into eliminating lectures and using technology to replace face-to-face interaction, the so-called 'active learning' strategy even before the pandemic. They moved towards promoting individualized teaching and enhancing interprofessional education $[11,12]$ through active learning strategies. The significant bulk of pre-clinical subjects can be conducted by various platforms, mostly through online, distance, or electronic learning without the face-to-face method. Subjects such as physiology, neuroscience, biochemistry, and medical genetics and pharmacology can be taught online. According to Miller's pyramid [13], most of the skills needed for these subjects are up to understanding the concepts. Hence, the need for face-to-face interaction is some extent, not as essential and manageable without face-to-face interactions and handson skills. But it is not the same case for courses like anatomy, clinical skills, microbiology, histology, and pathology, which require labs and hands-on experiences. However, for universities that incorporated clinical skills in the pre-clinical subjects, teaching these skills can only be done in theory through online resources. It can practice with standardized patients using telehealth/telemedicine concepts. We aimed to identify advantages and difficulties with this new approach as a necessary replacement for traditional face-to-face lectures. The changes implemented at AUSOM in the first two years of the medical school's education during the pandemic can be summarized as follows.

- Basic science instruction- Online didactic live lectures, group discussions, and virtual labs

- Basic science assessments- being conducted with video-based remote proctoring

- NBME comprehensive basic science exams- continuing with video-based proctoring by Zoom

Even though there is the existence of online teaching for quite some time in a few medical schools, especially during the preclinical period, there was not much literature on the outcomes or effectiveness of online teaching. This study aims to explore if online instruction emergency remote education was equally effective as on-campus teaching or less effective compared to on-campus teaching. This manuscript aims to investigate if online teaching emergency remote education served the purpose, the same as oncampus teaching. The outcomes that were compared between on-campus instruction and online teaching were course evaluations and students' performance on assessments (final grades). This might be the first of this kind of study comparing outcomes between on-campus teaching and online teaching.

Alternate Hypothesis: Online teaching is equally effective as face-to face teaching.

Null Hypothesis- Online teaching is not effective as face-to face teaching.

\section{Methods}


This is a mixed concurrent quantitative and qualitative research study. In September-December 2019 semester, the basic science instruction was completely on-campus. In January- April 2020 semester, the basic science instruction was on-campus till March 2020, but it became virtual from March $17^{\text {th }}$ due to lockdown implemented on the island. We didn't use the outcomes of January-April semester to compare with September-December 2019 semester as January-April semester had both on-campus and online teaching. May-August 2020 semester's outcomes which was completely online were compared with outcomes of September-December 2019 semester. Same faculty members were involved in teaching the same courses between September-December 2019 semester and May-August 2020 semester. The admission criteria and the attributes like GPA remain the same for students of September-December 2019 semester and May-August 2020 semesters. There were no changes in the admissions criteria for selection process of students. This study was approved by the Research and Ethics committee of AUSOM.

Quantitative data: Comprised of two components

- Course evaluations- comparison of course evaluations between September-December 2019 (complete on-campus and face-to-face) and May-August 2020 semesters (complete online instruction)

- Comparison of students' performance (Mean class average) in basic science courses between September-December 2019 and May-August 2020 semesters

Quantitative data were collected from the central IT department of AUSOM, where all course evaluations at the end of the semester are compiled using Survey Monkey. Dean's office and MEU gather this data every semester for analysis by the dean, quality assurance committee, and curriculum committee. The dean's office is using the same data to give feedback to faculty members. The questionnaire (course evaluations) included a total of sixteen questions (appendix 1). The responses to the questionnaire were gathered on the Likert scale of one to five. One is strongly disagreeing, two is disagreeing, three is neutral/no opinion, four is agreeing, and five is strongly agreeing. The values of mean and standard deviation were analyzed. SPPSS software was used to calculate $p$-values by using a t-test to determine any statistically significant difference. The $p$-values were adjusted to the nearest second decimal values. The students' performance (grades) on assessments was collected from the Students Information System (SIS). The assessments included multiple-choice questions, oral examinations, objective structured practical examinations, and standardized patient-based assessments. The examinations were similar between September-December 2019 and May-August 2020 semesters. The class averages were calculated using SPSS software and calculated the p-value using a t-test to examine any statistically significant difference. During the collection of data, no personal data was identified.

We also conducted individual interviews (qualitative data) with students and faculty members to gather their experiences and perceptions regarding online teaching. We did conduct a total of 19 interviews during September-October 2020. We randomly selected two students from each semester from MD1 to MD5 semesters, and a total of ten students were invited to participate in the interview. We invited all 12 
faculty members teaching basic since courses to participate in the interview. All participants are required to sign the consent form. The interview schedule consists of five questions (appendix, 2). All interviews took time around 10-15 minutes. Interviews were audio recorded. Interviews were conducted either by telephone or personally. Students who involved in this research study conducted all interviews. Students were trained on how to run the interviews by the principal investigator. The faculty authors did the data analysis. All interviews were recorded and transcribed using Happy Scribe software. After verification of its content, we read the transcript carefully line by line for familiarization. We used thematic analysis. The thematic analysis included familiarization, identifying a thematic framework, indexing, charting, and mapping and interpretation. Certain ideas cropped up in the transcript readily, and we gave these a preliminary code. Then we began to identify themes or emergent concepts and engaged in re-coding to develop more well-defined categories.

\section{Results}

The response rate for course evaluations was as follows. The response rate for Mind, Brain and Behavior 2 in September 2019 was eight out of 11 (73\%), and in May 2020 semester was 11 out of 13 (85\%). The response rate for Diseases, Immunity and Therapeutics 1 in September 2019 semester was nine out of 11 (82\%), and in May 2020 semester was 10 out of $14(71 \%)$. The response rate for Human Structure and Function 1 in September 2019 semester was 12 out of 12 (100\%), and in May 2020 semester was 19 out of $19(100 \%)$. The response rate for Human Structure and Function 2 in September 2019 semester was eight out of 10 (80\%), and in May 2020 semester was 10 out of 13 (77\%). For Clinical Skills I (CS 1), in September 2019 semester, the response rate was eight out of 10 (80\%), and in May 2020 semester was 17 out of 19 (89.4\%). The response rate for Clinical Skills 2 (CS-2) in September 2019 semester was nine out of nine (100\%), and in May 2020 semester, 16 out of $16(100 \%)$. We did not include evaluations of Mind, Brain and Behavior 1 and Diseases, Immunity and Therapeutics 2 in the data analysis as the response rate and sample size is too small for those two courses. Students' responses for most of the questions, mean values have no statistically significant difference $(p<0.05)$ between on-campus teaching and online teaching (Tables 1-4). Even if there is a difference, the mean values or students' responses were better with online teaching (Tables 1-4). Students' performance in assessments in each course was compared between September 2019 and May 2020 semesters. There was no statistically significant difference $(p<0.05)$ between the two semesters (Table 5) except for two courses, Mind, Brain and Behavior 2 and clinical skills 2.

We were able to interview all ten students out of ten students that were invited for the interviews $(100 \%$ response rate). We were able to interview nine faculty members out of 12 faculty members that were invited for an interview (75\% response rate). Thematic analysis of the qualitative data identified the following themes.

\section{Previous experience with online teaching and learning}


Most faculty members said they did not have any previous experiences with online teaching. Four faculty members did distance learning programs for their education. All other faculty members felt that this online teaching and training are new. Few students did some online courses in the past but not in the medical school. The students who did online programs before joining the medical school felt that it could help the students with part-time jobs. Most of the faculty members felt that they never thought of online teaching in medical school before the pandemic. One faculty member quoted that 'you do not have to have where people are coming together and using facilities. And so, you save space and save costs. But because they are learning and learning requires interaction, you know, person to person interaction and person-to-person questions require not only verbal but also nonverbal cues. And got much more from in person learning than you can ever get from online learning. (faculty interviewee no.3)'

One of the faculty members quoted that "I thought that online teaching would be useful and it is an additional benefit, like, you know, for example, if the student is already on campus and like an additional teaching, we can use the online teaching at the next level. So, I was thinking it like that, like, you know, as a pre-reading or like as a complementary educational tool after the class lecture (faculty interviewee 4).'

\section{Stimulators for online teaching}

All faculty members and students felt that the major stimulator for online teaching in the current circumstances is the ongoing pandemic of COVID-19. All of them felt that this pandemic forced us to do online teaching. To complete education, especially in this tough and unprecedented times, online instruction for basic science courses is the only option. One of the faculty members quoted that, 'we have all kinds of resources and technologies and this can be simulated on devices like laptops, mobiles, and then the students can learn and practice using those technologies that are available (faculty interviewee 1).'

The other major stimulator mentioned by students is saving time. One student quoted that, "I think it's time, even before if I wake up at 6 am, I will spend most of the time in getting dressed up for school and getting ready and now even though I wake up at $6 \mathrm{am}$ I will spend $15 \mathrm{~min}$ for fresh up, and I can use the rest of the time to pre-read (student interviewee 1).'Students also felt that online education could be helpful for students with financial issues and physical disabilities.

\section{Obstacles for online teaching}

The major barriers mentioned by faculty members and students are technological difficulties, power issues, and network problems, which can happen sometimes. Some of the faculty members might not understand or acknowledge the technical challenges that students are going through. The other obstacle is time differences (different time zones). This is especially an issue with synchronous online instruction. The other obstacle for synchronous online instruction is that faculty members get fatigued of online education as they are required to spend more time explaining the same concept, and it could have been done in less time in on-campus teaching. One student felt that some of the faculty members were not 
ready for online classes. One student felt that class could be very monotonous in online education when there is no personal interaction between the students and faculty members.

\section{Advantages of online teaching}

The major advantages of online teaching are the availability of many resources and technologies and complementing the didactic lectures with these technologies. Online teaching is very convenient and flexible. The other advantage cited by the faculty members and students is that online teaching can have sessions recorded and recorded videos can be played again. Students can always go back to the point where there was a conclusion that, as in in-person lectures, we can't do that. The other advantage mentioned was that faculty and students could be anywhere in the world. One of the most important advantages mentioned by students is saving time with online teaching, as they are not required to go to the school's campus. The other advantage is that introverts and shy students became very communicative and interacting well during online classes.

\section{Disadvantages of online teaching}

Most of the faculty members and students felt that the major obstacle for online teaching is the lack of hands-on experiences and personal interaction. Even though we were conducting virtual labs, some faculty members and students felt that they are missing labs and hands-on experiences, especially for courses like anatomy and clinical skills. Online teaching is lacking classroom experience, which is the major disadvantage of missing personal connection. One faculty member quoted that there is verbal communication and there is nonverbal communication. As a teacher, you can look into the students' eyes and ask them questions, and they can look into the teacher's eye and answer or ask questions also (faculty interviewee 3).'Professional training requires visual, auditory, tactile, and every part of your faculties to be ministering to the student. Sometimes students can switch off the camera and disappear from the class. Some faculty members quoted that it is very difficult to track students' attendance during class hours.

Another disadvantage associated with online teaching is the lack of motivation for students. Procrastination is one of the problems in online learning and training. Students must be kept motivated, and communication between faculty and students is the key. One of the faculty members quoted that, 'the main obstacle for online teaching is the self-motivation of the students that might be missing. In face-to-face interactions, they learn from group studies and with the faculty interaction and then the personal experiences that they do have and then hands-on experiences. They are missing like a lot of group interaction (faculty interviewee 7).'

\section{Discussion}

The COVID-19 pandemic is continuing and will remain to disrupt medical teaching and training. COVID-19 has caused unprecedented interruption to the medical education process and healthcare across the globe [14]. It is still uncertain when medical students across the globe will be able to return to campuses. The 
current COVID-19 pandemic presented various challenges like challenges to faculty in shifting from faceto-face to online teaching, challenges to students in moving to online learning, challenges in conducting the assessment, challenges in accessing the internet and using digital technology, and challenges to an institution in organizing online teaching and learning activities during the lockdown. It is said that challenges bring opportunities. COVID-19 may also bring opportunities. Medical educators have initiated the process of transforming education and improving quality before the COVID-19 outbreak. The COVID19 pandemic has, however, changed the landscape of medical education. The situation has currently forced medical educationalists to think 'out of the box' and act innovatively using advanced digital technology. The existing COVID-19 pandemic has forced and motivated us to transform education method, modality, and process, which may demand greater effort initially. Still, it provides teacher, faculty, and facilitator impetus to keep pace with current technology trends, e.g., digital gadgets, programs, and software, modified forms of media with innovative audiovisual aids. This is a new experience or opportunity to learn, understand, and update unique needs and new modes of delivery of medical education for all stakeholders involved. It may also have a long-lasting impact on healthcare.

The attitude and readiness of educators running or engaging in online education are crucial. As key stakeholders, educators should be seen as educators and be supported and developed as such, including the faculty development in both delivery and design of online teaching [15]. This could be evident in our efforts to emphasize the requirement of faculty development activities for our biomedical educators. This led to the successful implementation of online teaching for our basic science courses, which is evident in course evaluations.

The literature on online learning in medical students before the COVID-19 pandemic has found that though students feel it complements their education, they do not see it as an acceptable replacement for in-person learning $[16,17]$. By now, many medical schools have created online coursework so that students can continue education and training from home $[18,19]$. In most medical institutions, alternative virtual coursework was adopted, such as e-learning modules, video vignettes, and virtual reality simulators [20]. Although the significant amount of time in the medical curriculum in pre-clerkship is allotted for didactic lectures, anatomy labs (Grant's Dissector Videos), clinical skills lab sessions (telemedicine/telehealth concepts), small group sessions, Problem-based Learning (PBL) sessions, and other labs (virtual labs like virtual microscopy in histology and pathology) at AUSOM also implemented and incorporated in online teaching and training. This allowed the active engagement and participation of students during online instruction. This could be evident from course evaluations. The last but one question on the survey (courses evaluations) is that if students contribute constructively to in-class activities, there is no statistically significant difference between the semesters of on-campus teaching and online teaching (Tables 1-4). We recommend adapting interactive online learning lectures using highly sophisticated technologies and virtual clinical case-based discussions. Such measures would help students adjust to this way of medical teaching.

Students' responses for the questions (course evaluations), questions from 1 to 7 are related to teaching methods including instructor stimulated student's interest in the subject, the instructor encouraged 
discussions and responded to questions, and the instructor used various instructional methods to reach the course objectives. Questions from 8 to 12 are related to the assessments and providing feedback, including feedback was provided within the stated time frame, feedback showed how to improve students' work, and the course procedures and assignments support course objectives. Questions from 13 to 16 are related to overall, how students' experience in this course, students contributed constructively to in-class activities and students' perception of achieving course learning objectives. Students' responses for most of the questions, mean values have no statistically significant difference $(p<0.05)$ between on-campus teaching and online teaching (Tables 1-4). Even if there is a difference, the mean values or students' responses were better with online teaching (Tables 1-4). Students' performance in assessments in each course was compared between September 2019 and May 2020 semesters. There was no statistically significant difference $(p<0.05)$ between the two semesters (Table 5$)$ except for two courses, Mind, Brain and Behavior 2 and clinical skills 2.

Even though the quantitative data have shown no statistically significant difference between on-campus teaching and online teaching, we did interviews to investigate if both quantitative and qualitative data complement each other. The data analysis of interviews has shown both advantages and disadvantages to online teaching. The advantages include the availability of different technologies, resources, and platforms for online teaching. The other advantage is online teaching is flexible and convenient. The other most important advantage is saving time for students as they do not need to get prepared and travel to the campuses. Students and faculty are well adopted during the difficult and unprecedented times. All students and faculty agreed that online teaching is the only option to teach basic science courses during this pandemic as campuses are not open. This change in medical education is seen as an emergency change rather than as a normal change process.

But most of the faculty members and students also have expressed their dissatisfaction with online teaching. The main disadvantage of online teaching is the lack of classroom experience and personal interaction. The other disadvantage is limitations on labs and hands-on experiences even though virtual labs are conducted. This was of major concern for anatomy and clinical skills courses. The biggest challenge for students is not having study groups as they are not on campus and lacking motivation. This can be rectified if students contact their peers using social media and online platforms and adequate communication with their faculty members. The other difficulties with online teaching are technical challenges and network issues.

\section{Conclusions}

We found that medical students had different knowledge, attitudes, and practices regarding the online learning process. Our results, especially quantitative data, have shown no statistically significant difference in either course evaluations or students' performance on assessments. This shows that online emergency remote education served the purpose in the first two years of medical school during the COVID-19 pandemic. The thematic analysis of interviews revealed the advantages and disadvantages of online teaching. The advantages of online instruction are flexibility and comfort, and students are able to 
save time. The disadvantages are technical challenges, network issues, students lacking motivation, lack of personal interaction, and limitations on lab and hands-on experiences. The results may not be generalized to other institutions. Further studies in different institutions must validate them to see online learning platform's utility as a teaching and learning mode, especially for basic science courses. Such replication studies in multiple institutions could help determine whether online education can replace traditional medical lectures in the first two years of medical school. Medical schools might look at didactic lectures that can be online, and small group discussions, seminars, and labs require on campus instruction. Online education in the first two years of medical school can be successful if students and faculty are appropriately engaged and actively involved in-class activities. Provide structure to the classroom activities, give students time, and provide feedback to students to make online education successful.

\section{Limitations}

This study was conducted at a single institution. Another limitation is the cross-sectional nature of the study design. This necessitates the requirement of conducting longitudinal studies in different institutions. Another limitation of our study is the small sample size that was used for quantitative data. But the sample size for qualitative data is adequate as we were able to do 19 interviews, and there was no further new information added after certain interviews.

\section{Declarations}

Conflict of Interest The authors declare that they have no conflict of interest.

Ethical Approval This study is approved by the Research and Ethics committee of Avalon University School of Medicine.

Informed Consent Informed written consent was taken from all participants (students and faculty members) and they had a right to decline participation in this study.

Consent for Publication: We haven't used any identifiable personal information or $3^{\text {rd }}$ party images or videos.

Funding: No external funding or internal funding received

Acknowledgements: Authors would like to acknowledge all faculty members and students who participated in the interviews.

\section{Authors' contributions}

- Sateesh Arja- Design of the study, data collection, qualitative data analysis, drafting the article, revision of the article, and final approval 
- Samir Fatteh- - Design of the study, data collection, drafting the article, revision of the article, and final approval

- Sailaja Nandennagari- - Design of the study, data collection, drafting the article, revision of the article, and final approval

- Sai Sarath Kumar Pemma- - Design of the study, data collection, drafting the article, revision of the article, and final approval

- Kumar Ponnusamy- - Design of the study, data collection, drafting the article, revision of the article, and final approval

- Sireesha Bala A.-- Design of the study, quantitative data analysis, drafting the article, revision of the article, and final approval

Data and Materials- Data and materials are avail be for repository.

\section{References}

1. Carlson, E. R. (2020) 'COVID-19 and Educational Engagement', Journal of Oral and Maxillofacial Surgery. https://doi.org/10.1016/j.joms.2020.04.033.

2. Collins B, Day R, Hamilton J, Legris K, Mawdsley H, Walsh T. 12 Tips for Pivoting to Teaching in a Virtual Environment. MedEdPublish 1-11

3. DeFilippis, E. M., Stefanescu Schmidt, A. C. and Reza, N. (2020) 'Adapting the Educational Environment for Cardiovascular Fellows-in-Training During the COVID-19 Pandemic', Journal of the American College of Cardiology, 75(20), pp. 2630-2634. https://doi.org/10.1016/j.jacc.2020.04.013.

4. Prem, K., Liu, Y., Russell, T. W., Kucharski, A. J., et al. (2020) 'The effect of control strategies to reduce social mixing on outcomes of the COVID-19 epidemic in Wuhan, China: a modelling study', The Lancet Public Health. Elsevier, 5, pp. e261-e270. https://doi.org/10.1016/S2468-2667(20)30073-6.

5. Rose, S. (2020) 'Medical Student Education in the Time of COVID-19', JAMA, 323(21), pp. 21312132, http://dx.doi.org/10.1001/jama.2020.5227.

6. Mian A, Khan S. Medical education during pandemics: a UK perspective. BMC Med. 2020;18(1):100. Published 2020 Apr 9. doi:1186/s12916-020-01577-y

7. Moszkowicz D, Duboc H, Dubertret C, Roux D, Bretagnol F. Daily medical education for confined students during COVID-19 pandemic: A simple video conference solution [published online ahead of print, 2020 Apr 6]. Clin Anat. 2020;10.1002/ca.23601. doi:1002/ca.23601

8. Aneesa Abdul Rashid, Mohd Radzniwan A. Rashid, Mohamad Nurman Yaman, Irfan Mohamad. Teaching Medicine Online During the COVID-19 Pandemic: A Malaysian Perspective. Bangladesh Journal of Medical Science, Vol : 19 Special Issue on Covid19, 2020.

9. Lowenthal, P., Borup, J., West, R. Archambault, L. Thinking Beyond Zoom: Using Asynchronous Video to Maintain Connection and Engagement During the COVID-19 Pandemic. Journal of Technology 
and Teacher Education. 2020. 28(2), 383-391. Waynesville, NC USA: Society for Information Technology \& Teacher Education. https://www.learntechlib.org/primary/p/216192/.

10. Mukhtar K, Javed K, Arooj M, Sethi A. Advantages, Limitations and Recommendations for online learning during COVID-19 pandemic era. Pak J Med Sci. 2020;36(COVID19-S4): S27-S31. doi:12669/pjms.36.COVID19-S4.2785.

11. Irby DM, Cooke M, O'Brien BC. Calls for reform of medical education by the Carnegie Foundation for the Advancement of Teaching: 1910 and 2010. Acad Med. 2010;85(2):220-227. doi:1097/ACM.0b013e3181c88449.

12. Skochelak SE, Stack SJ. Creating the Medical Schools of the Future. Acad Med. 2017;92(1):16-19. doi:10.1097/ACM.0000000000001160.

13. Miller GE. The assessment of clinical skills/competence/performance. Acad Med. 1990;65:S63-7. doi: 10.1097/00001888-199009000-00045.

14. Woolliscroft JO. Innovation in Response to the COVID-19 Pandemic Crisis. Acad Med. 2020 Aug;95(8):1140-1142. doi: 1097/ACM.0000000000003402

15. Baran E, Correia AP. A professional development framework for online teaching. TechTrends 2014; 58: 96-102.

16. Ruiz JG, Mintzer MJ, Leipzig RM. The impact of e-learning in medical education. Academic Medicine. 2006;81 (3):207-212. DOI: 1097/00001888-200603000-00002

17. Huynh R. The role of E-learning in medical education. Academic Medicine. 2017;92(4):430. DOI: 1097/ACM.0000000000001596

18. Evans DJR, Bay BH, Wilson TD, et al. Going virtual to support anatomy education: A STOP GAP in the midst of the Covid-19 pandemic. Anatomical Science Education. 2020 April 10. Published online. DOI: 1002/ase.1963

19. Srinivasan DK. Medical students' perceptions and an anatomy teacher's personal experience using an e-learning platform for tutorials during the Covid-19 crisis. Anat Sci Educ. 2020 May 6. Published online. DOI:1002/ase.1970

20. Lim EC, Oh VM, Koh DR, Seet RC. The challenges of "continuing medical education" in a pandemic era. Ann Acad Med Singap. 2009 Aug;38(8):724-6. DOI: 1097/00152193-200601000-00041

\section{Tables}

Table 1: Comparison of Course evaluations for the courses Mind, Brain and Behavior (MBB) 2 


\begin{tabular}{|c|c|c|c|}
\hline \multirow[t]{4}{*}{ Question Number } & MBB-2 & MBB-2 & P-Value \\
\hline & Sep 2019 & May 2020 & t-test \\
\hline & $\mathrm{N}=8$ & $N=11$ & \\
\hline & Mean \pm SD & Mean \pm SD & \\
\hline Q1 & $4.13 \pm 0.78$ & $3.91 \pm 1.08$ & 0.63 \\
\hline Q2 & $4.00 \pm 0.53$ & $4.27 \pm 0.62$ & 0.33 \\
\hline Q3 & $4.14 \pm 0.35$ & $4.36 \pm 0.64$ & 0.39 \\
\hline Q4 & $4.29 \pm 0.45$ & $4.18 \pm 0.57$ & 0.66 \\
\hline Q5 & $4.14 \pm 0.35$ & $4.45 \pm 0.50$ & 0.15 \\
\hline Q6 & $4.00 \pm 0.53$ & $4.55 \pm 0.50$ & 0.03 \\
\hline Q7 & $4.00 \pm 0.53$ & $4.27 \pm 0.45$ & 0.25 \\
\hline Q8 & $4.17 \pm 0.37$ & $4.45 \pm 0.50$ & 0.20 \\
\hline Q9 & $4.17 \pm 0.37$ & $4.45 \pm 0.50$ & 0.20 \\
\hline Q10 & $3.83 \pm 0.90$ & $4.27 \pm 0.62$ & 0.22 \\
\hline Q11 & $4.17 \pm 0.37$ & $4.55 \pm 0.50$ & 0.09 \\
\hline Q12 & $4.17 \pm 0.37$ & $4.36 \pm 0.48$ & 0.36 \\
\hline Q13 & $4.17 \pm 0.37$ & $4.36 \pm 0.64$ & 0.46 \\
\hline Q14 & $3.50 \pm 0.50$ & $3.82 \pm 1.19$ & 0.49 \\
\hline
\end{tabular}




\begin{tabular}{|llll|}
\hline Q15 & $4.17 \pm 0.69$ & $4.00 \pm 1.04$ & 0.69 \\
\hline Q16 & $4.00 \pm 0.58$ & $3.82 \pm 1.19$ & 0.70 \\
\hline
\end{tabular}

Note: Statistically significant p-values are in bold

Table 2: Comparison of Course evaluations for the courses Diseases, Immunity and Therapeutics (DIT) I 


\begin{tabular}{|c|c|c|c|}
\hline \multirow[t]{4}{*}{ Question Number } & DIT- 1 & DIT-1 & P-value \\
\hline & Sep 2019 & May 2020 & t-test \\
\hline & $\mathrm{N}=9$ & $N=10$ & \\
\hline & Mean \pm SD & Mean \pm SD & \\
\hline Q1 & $4.44 \pm 0.68$ & $4.25 \pm 0.60$ & 0.53 \\
\hline Q2 & $4.44 \pm 0.68$ & $3.92 \pm 0.95$ & 0.19 \\
\hline Q3 & $4.44 \pm 0.68$ & $4.17 \pm 0.55$ & 0.35 \\
\hline Q4 & $4.44 \pm 0.68$ & $4.25 \pm 0.60$ & 0.53 \\
\hline Q5 & $4.56 \pm 0.68$ & $4.33 \pm 0.62$ & 0.45 \\
\hline Q6 & $4.33 \pm 0.67$ & $4.08 \pm 0.76$ & 0.46 \\
\hline Q7 & $4.22 \pm 0.79$ & $4.09 \pm 0.51$ & 0.67 \\
\hline Q8 & $4.50 \pm 0.71$ & $4.17 \pm 0.69$ & 0.32 \\
\hline Q9 & $4.25 \pm 1.30$ & $4.33 \pm 0.75$ & 0.87 \\
\hline Q10 & $4.25 \pm 0.97$ & $4.08 \pm 0.76$ & 0.67 \\
\hline Q11 & $4.57 \pm 0.49$ & $4.17 \pm 0.69$ & 0.17 \\
\hline Q12 & $4.29 \pm 0.45$ & $4.33 \pm 0.62$ & 0.87 \\
\hline Q13 & $4.43 \pm 0.49$ & $4.08 \pm 0.76$ & 0.26 \\
\hline
\end{tabular}




\begin{tabular}{|llll|}
\hline Q14 & $4.00 \pm 1.00$ & $3.83 \pm 0.90$ & 0.70 \\
\hline Q15 & $4.57 \pm 0.49$ & $4.33 \pm 0.62$ & 0.37 \\
\hline Q16 & & & \\
& $4.00 \pm 1.31$ & $4.17 \pm 0.55$ & 0.71 \\
\hline
\end{tabular}

Table 3: Comparison of Course evaluations for the courses Human Structure and Function (HSF) 1 and 2 


\begin{tabular}{|c|c|c|c|c|c|c|}
\hline \multirow[t]{4}{*}{ Question Number } & HSF- 1 & HSF-1 & P-Value & HSF-2 & HSF-2 & P-Value \\
\hline & Sep 2019 & May 2020 & t-test & Sep 2019 & May 2020 & t-test \\
\hline & $\mathrm{N}=12$ & $N=19$ & & $N=8$ & $N=10$ & \\
\hline & Mean \pm SD & Mean \pm SD & & Mean \pm SD & Mean \pm SD & \\
\hline Q1 & $4.42 \pm 0.76$ & $4.00 \pm 0.73$ & 0.14 & $4.25 \pm 0.83$ & $4.22 \pm 0.63$ & 0.93 \\
\hline Q2 & $4.50 \pm 0.65$ & $4.16 \pm 0.81$ & 0.23 & $4.25 \pm 0.66$ & $4.00 \pm 0.89$ & 0.52 \\
\hline Q3 & $4.50 \pm 0.65$ & $4.26 \pm 0.64$ & 0.32 & $4.75 \pm 0.43$ & $4.30 \pm 0.90$ & 0.21 \\
\hline Q4 & $4.58 \pm 0.49$ & $4.32 \pm 0.65$ & 0.25 & $4.63 \pm 0.48$ & $4.10 \pm 0.83$ & 0.13 \\
\hline Q5 & $4.42 \pm 0.76$ & $4.47 \pm 0.50$ & 0.83 & $4.75 \pm 0.66$ & $4.20 \pm 0.87$ & 0.16 \\
\hline Q6 & $4.42 \pm 0.76$ & $4.32 \pm 0.73$ & 0.72 & $4.38 \pm 0.70$ & $4.10 \pm 0.83$ & 0.46 \\
\hline Q7 & $4.17 \pm 0.99$ & $4.00 \pm 0.75$ & 0.59 & $4.13 \pm 0.78$ & $4.11 \pm 1.20$ & 0.97 \\
\hline Q8 & $3.83 \pm 1.28$ & $3.84 \pm 0.99$ & 0.98 & $4.13 \pm 0.60$ & $4.10 \pm 1.22$ & 0.95 \\
\hline Q9 & $4.17 \pm 1.07$ & $4.05 \pm 0.60$ & 0.69 & $4.13 \pm 0.60$ & $4.00 \pm 1.10$ & 0.77 \\
\hline Q10 & $3.92 \pm 1.11$ & $3.89 \pm 0.64$ & 0.92 & $3.88 \pm 0.78$ & $3.70 \pm 1.10$ & 0.70 \\
\hline Q11 & $3.83 \pm 0.99$ & $3.79 \pm 0.89$ & 0.91 & $4.25 \pm 0.66$ & $3.90 \pm 1.04$ & 0.42 \\
\hline Q12 & $4.00 \pm 0.91$ & $4.05 \pm 0.60$ & 0.85 & $4.25 \pm 0.66$ & $4.00 \pm 0.77$ & 0.48 \\
\hline Q13 & $4.17 \pm 0.90$ & $4.00 \pm 0.92$ & 0.62 & $4.13 \pm 0.93$ & $3.60 \pm 1.20$ & 0.32 \\
\hline
\end{tabular}




\begin{tabular}{|lllllll|}
\hline Q14 & $3.58 \pm 1.04$ & $3.42 \pm 0.99$ & 0.67 & $4.13 \pm 0.60$ & $3.50 \pm 1.12$ & 0.17 \\
\hline Q15 & $4.25 \pm 1.16$ & $4.11 \pm 1.05$ & 0.67 & $4.50 \pm 0.50$ & $4.20 \pm 0.75$ & 0.35 \\
& & & & & & \\
\hline Q16 & $3.58 \pm 1.11$ & $4.00 \pm 1.05$ & 0.30 & $3.38 \pm 0.48$ & $3.60 \pm 1.11$ & 0.61 \\
\hline
\end{tabular}

Table 4: Comparison of Course evaluations for clinical skills 1 and 2 courses 


\begin{tabular}{|c|c|c|c|c|c|c|}
\hline \multirow[t]{4}{*}{ Question Number } & CS-1 & CS-1 & P-Value & CS-2 & CS-2 & P-Value \\
\hline & Sep 2019 & May 2020 & t-test & Sep 2019 & May 2020 & t-test \\
\hline & $N=8$ & $\mathrm{~N}=17$ & & $N=9$ & $N=16$ & \\
\hline & Mean \pm SD & Mean \pm SD & & Mean \pm SD & Mean \pm SD & \\
\hline \multirow[t]{2}{*}{ Q1 } & $3.88 \pm 1.17$ & $4.41 \pm 1.02$ & 0.26 & $3.86 \pm 1.36$ & $4.56 \pm=0.50$ & \\
\hline & & & & & & 0.07 \\
\hline Q2 & $4.25 \pm 0.66$ & $4.53 \pm 0.84$ & 0.42 & $4.14 \pm 1.36$ & $4.67 \pm 0.47$ & 0.17 \\
\hline Q3 & $4.13 \pm 0.93$ & $4.53 \pm 0.61$ & 0.21 & $3.86 \pm 1.36$ & $4.78 \pm 0.42$ & 0.02 \\
\hline Q4 & $4.25 \pm 0.66$ & $4.47 \pm 0.61$ & 0.42 & $4.00 \pm 1.31$ & $4.78 \pm 0.42$ & 0.04 \\
\hline Q5 & $3.75 \pm 0.83$ & $4.24 \pm 0.70$ & 0.14 & $4.67 \pm 0.47$ & $4.78 \pm 0.42$ & 0.55 \\
\hline Q6 & $3.50 \pm 0.87$ & $4.41 \pm 0.88$ & 0.02 & $3.83 \pm 1.07$ & $4.89 \pm 0.31$ & 0.00 \\
\hline Q7 & $3.88 \pm 1.05$ & $4.53 \pm 0.69$ & 0.07 & $4.17 \pm 0.37$ & $4.56 \pm 0.50$ & 0.05 \\
\hline Q8 & $4.13 \pm 0.60$ & $4.47 \pm 0.61$ & 0.20 & $3.67 \pm 1.25$ & $4.63 \pm 0.48$ & 0.01 \\
\hline Q9 & $4.13 \pm 0.78$ & $4.41 \pm 0.61$ & 0.34 & $3.50 \pm 1.26$ & $4.50 \pm 0.50$ & 0.01 \\
\hline Q10 & $3.63 \pm 1.22$ & $4.24 \pm 0.77$ & 0.14 & $3.00 \pm 1.53$ & $4.38 \pm 0.70$ & 0.00 \\
\hline Q11 & $4.00 \pm 0.87$ & $4.47 \pm 0.81$ & 0.20 & $4.40 \pm 0.49$ & $4.57 \pm 0.49$ & 0.41 \\
\hline Q12 & $4.00 \pm 0.71$ & $4.44 \pm 0.62$ & 0.13 & $4.40 \pm 0.49$ & $4.50 \pm 0.50$ & 0.63 \\
\hline Q13 & $4.00 \pm 0.71$ & $4.38 \pm 0.61$ & 0.18 & $3.80 \pm 0.75$ & $4.50 \pm 0.50$ & 0.01 \\
\hline
\end{tabular}




\begin{tabular}{|lllllll|}
\hline Q14 & $3.25 \pm 1.30$ & $4.12 \pm 0.60$ & 0.03 & $3.50 \pm 0.96$ & $4.44 \pm 0.50$ & 0.00 \\
\hline Q15 & $4.5 \pm 1.00$ & $4.44 \pm 0.50$ & 0.84 & $4.33 \pm 0.47$ & $4.50 \pm 0.50$ & 0.41 \\
\hline Q16 & $4.25 \pm 0.97$ & $4.50 \pm 0.61$ & 0.43 & $4.33 \pm 0.47$ & $4.63 \pm 0.48$ & 0.14 \\
\hline
\end{tabular}

Note: Statistically significant p-values are in bold

Table 5: Comparison of students' performance in different courses between two semesters

\begin{tabular}{|llll|}
\hline Course name & $\begin{array}{l}\text { Class performance mean value } \\
\text { Sep } 2019 \\
\text { Mean } \pm \text { SD }\end{array}$ & $\begin{array}{l}\text { Class performance mean value } \\
\text { May } 2020 \\
\text { Mean } \pm \text { SD }\end{array}$ & $\begin{array}{c}\text { P-value } \\
\text { t-test }\end{array}$ \\
\hline MBB I & $84.89 \pm 6.77(\mathrm{~N}=9)$ & $81.50 \pm 7.59(\mathrm{~N}=14)$ & 0.29 \\
\hline MBB 2 & $85.09 \pm 6.66(\mathrm{~N}=11)$ & $77.43 \pm 6.60(\mathrm{~N}=13)$ & 0.01 \\
\hline DIT 1 & $76.64 \pm 5.89(\mathrm{~N}=11)$ & $76.71 \pm 8.58(\mathrm{~N}=14)$ & 0.98 \\
\hline DIT 2 & $76.56 \pm 3.74(\mathrm{~N}=18)$ & $79.33 \pm 6.08(\mathrm{~N}=12)$ & 0.13 \\
\hline HSF 1 & $80.2 \pm 7.62(\mathrm{~N}=10)$ & $78.68 \pm 6.38(\mathrm{~N}=17)$ & 0.58 \\
\hline HSF 2 & $75 \pm 5.53(\mathrm{~N}=12)$ & $75.38 \pm 4.10(\mathrm{~N}=13)$ & 0.85 \\
\hline Clinical Skills 1 & $92.1 \pm 5.3(\mathrm{~N}=10)$ & $91.11 \pm 4.24(\mathrm{~N}=19)$ & 0.59 \\
\hline Clinical Skills 2 & $94.67 \pm 3.65(\mathrm{~N}=9)$ & $87.63 \pm 6.72(\mathrm{~N}=16)$ & 0.01 \\
\hline
\end{tabular}

Note: Statistically significant p-values are in bold

\section{Supplementary Files}

This is a list of supplementary files associated with this preprint. Click to download.

- Appendix1.pdf

- Appendix2.pdf 